\title{
Obesity in Egyptian Children: Influence of Oxidant-Antioxidant Status on Lipid and Glucose Homeostasis
}

\author{
Fatma SE Ebeid $^{1 *}$, Alaa Y Baioumi ${ }^{1}$, Fatma Elzaree ${ }^{2}$ and Fatma A Ibrahim ${ }^{3}$ \\ ${ }^{1}$ Department of Paediatrics, Faculty of Medicine, Ain Shams University, Egypt \\ ${ }^{2}$ Department of Child Health, National Research Centre, Cairo, Egypt \\ ${ }^{3}$ Department of Biochemistry, National Research Centre, Egypt
}

"Corresponding author: Fatma Soliman Elsayed Ebeid, 2 Lotfy Elsayed St. Ain Shams University staff's Campus, Cairo, Egypt, Tel: 0020109959596; E-mail: dr.fatma_ebeid@yahoo.com

Received date: June 18, 2018; Accepted date: July 19, 2018; Published date: July 30, 2018

Copyright: $\odot 2018$ Ebeid FSE, et al. This is an open-access article distributed under the terms of the Creative Commons Attribution License, which permits unrestricted use, distribution, and reproduction in any medium, provided the original author and source are credited.

\begin{abstract}
Aim: We aimed to assess antioxidant status in Egyptian children with obesity and investigate the mutual relationship between oxidative stress markers, body composition, and metabolic pattern.

Methods: This cross-sectional study included 52 obese and 20 healthy-weight children. Subjects underwent through clinical assessment. Serum lipid profile, fasting glucose, and serum insulin were measured in plasma. A range of antioxidant activities was tested. Steady state beta cell function (\%B), insulin sensitivity (\%S), and insulin resistance (IR) were calculated.

Results: Children with obesity had high prevalence of family history of obesity, hypertension and type 2 diabetes and 18 of them had hypertension. Sixteen $(30.7 \%)$ children with obesity had high level $\left(90^{\text {th }}\right.$ percentiles) of lowdensity lipoprotein (LDL-C) and triglycerides and $14(24.9 \%)$ had low level (10 percentiles) of high-density lipoprotein (HDL-C). Plasma malondialdehyde (MDA), glutathione-S-transferase (GST) were significantly higher, whereas catalase, total antioxidant capacity (TAC), and vitamin E were significantly lower in children with obesity. Both MDA and GST correlated positively with anthropometric measures, triglycerides, fasting insulin, and HOMA-IR. Both catalase and TAC correlated negatively with anthropometric measures, and cholesterol. Furthermore, catalase correlated negatively with diastolic blood pressure, triglycerides, LDL, fasting insulin, and HOMA-IR, but positively with age.
\end{abstract}

Conclusion: There is a substantial burden of oxidative stress represented by the high level of oxidants (MDA, GST) and low level of antioxidants (catalase, TAC) in children with obesity necessitating improvement in the management of childhood obesity.

Keywords: Oxidant-antioxidant status; Glucose hemostasis; Childhood obesity; Egyptian children

\section{Introduction}

Childhood obesity is one of the most alarming health problems in both developed and developing world [1], with distressing health consequences such as dyslipidemia, atherosclerosis, and cardiovascular disease (CVD) [2]. Oxidative stress represents an imbalance between tissue oxidants in form of free radicals or reactive oxygen species (ROS) and antioxidants. This imbalance may be a unifying mechanism in the development of major obesity-related comorbidities [3]. There are several potential contributors to oxidative stress in obesity, including hyperglycaemia, increased muscle activity to carry excessive weight, elevated tissue lipid levels, inadequate antioxidant defenses, chronic inflammation, and endothelial ROS production. Not all of these factors are equally involved, one contributor may exert a greater oxidative stress effect than the others [4].

Despite the increasing prevalence of obesity and obesity-related complications in Egyptian children, there are few studies on prepubertal children with obesity. In addition the oxidant-antioxidant enzymes and their correlations with the glucose and lipid profile have not been fully studied. The present study aimed at assessment of oxidant and antioxidant activities in Egyptian children with obesity and comparison to their normal-weight counterparts. Furthermore, we aimed at investigating the mutual relationship between oxidative stress markers, body composition, and metabolic pattern in childhood obesity.

\section{Subjects and Methods}

This was a cross-sectional study, conducted at the Paediatrics Hospital, Ain Shams University in Cairo, Egypt. Fifty-two children and adolescents with obesity, defined as a BMI at or above the $95^{\text {th }}$ percentile for children and teens of the same age and sex [5] were recruited. Twenty age- and sex-matched healthy-weight children served as a control group, they were recruited from the General Outpatient Clinic with no family history of obesity, diabetes or hypertension. Children with hyperglycaemia and inherited obesity were excluded.

The study design and clinical and laboratory assessments were explained and informed consent was obtained from each child and/or 
their legal guardians before enrolment in the study. The study was approved by the institutional regulatory board (IRB) of the Paediatrics Hospital, Ain Shams University and were in accordance with the code of ethics of the world medical association (Declaration of Helsinki) for experiments in humans, 1975.

\section{Medical history}

It was obtained directly by interviewing the patient and their legal guardians with special emphasis on demographic characteristics, and family history of obesity, hypertension and diabetes.

\section{Anthropometric measures}

Anthropometric measures of every patient and control were conducted by two trained investigators to overcome inter-rater error. Height was measured to the nearest centimeter with a portable stadiometer (Seca, Marsden, UK). Weight was measured to the nearest kilogram using electronic digital scales (Tanita Corporation, Tokyo, Japan). Body mass index (BMI) values were calculated using measured height and weight values [weight (kilograms)/height $\left(\right.$ meter $\left.^{2}\right)$ ]. Anthropometric Z-scores were calculated relative to age- and genderspecific norms produced by the Center for Disease Control (CDC) from National Health and Nutrition Examination Survey (NHANES) III data [6]. Waist-to hip ratio (WHR) were calculated as ratio of waist circumference at its smallest point between the iliac crest and the rib cage to hip circumference at its largest width over the greater trochanters.

\section{Blood pressure}

It was measured using a proper pediatric cuff size mercury gravity manometer and the blood pressure percentiles were determined. Prehypertension was defined as an average systolic or diastolic blood pressure that fell between $90^{\text {th }}$ to $<95^{\text {th }}$ percentile, hypertension was defined as an average systolic or diastolic blood pressure that was on the $95^{\text {th }}$ percentile or greater based on at least three separate readings, according to The National High Blood Pressure Education Program [7]. Physical assessment was performed with special focus on obesityrelated morbidities. Puberty was assessed and classified according to Tanner stage into pre-pubertal (Tanner stage 1), in puberty (Tanner stage 2-3), and completing puberty (Tanner stage 4-5) [8].

\section{Blood samples}

These samples were freshly withdrawn following an overnight fasting on heparinized-tubes, placed in an icebox and immediately transferred to laboratory at the National Research Institute. Samples were centrifuged immediately at $4000 \mathrm{rpm}$ at $4^{\circ} \mathrm{C}$ and plasma was stored at $-20^{\circ} \mathrm{C}$ until analysis. Fifty microliter of RBC were lysed with $1.0 \mathrm{~mL}$ ice cold water, then the clear lysate obtained after spinning down the cell debris at $8500 \mathrm{~g}$ at $4^{\circ} \mathrm{C}$ for $10 \mathrm{~min}$ was used for the analysis.

Blood glucose concentration was measured spectrophotometrically (Boeco S-20 Spectrophotometer, Hamburg, Germany) using an enzymatic test kit (glucose oxidase, Biodiagnostic, Cairo, Egypt) [9].

Fasting serum insulin was quantitatively determined by an enzymelinked immunosorbent assay (ELISA) kit (Ultrasensitive human Insulin ELISA from Mercodia).
The updated Homeostasis Model Assessment (HOMA2) was used to estimate steady state beta cell function (\%B) and insulin sensitivity $(\% \mathrm{~S})$, as percentages of a normal reference population, in addition insulin resistance (IR) was calculated using the HOMA calculator [10].

Lipid Profile: Serum cholesterol and triglyceridess (TG) were estimated by enzymatic methods [11] using diagnostic kits (Beckman AU480). High-density lipoprotein (HDL-C) was measured in the serum after precipitation with phosphotungstic acid in presence of magnesium chloride. Low-density lipoprotein (LDL-C) was estimated using the formula of Friedewald et al. [12] with modification of Bachorik [13]. Quality control was maintained using quality control sera of Technicon (Bayer Corporation, USA). The intra assay and inter assay coefficient of variations were between $4 \%$ and $6 \%$ that was well within the recommended range, suggested by National Cholesterol Education Program (NCEP). Lipid profiles were classified According to NCEP Expert Panel on Cholesterol Levels in Children [14] as follows:

- LDL-C: Acceptable, borderline-high ( $75^{\text {th }}$ percentiles), and high $\left(90^{\text {th }}\right.$ percentiles) were $<110,110-129$, and $130 \mathrm{mg} / \mathrm{dL}$ respectively.

- TG level for those from 0-9 years: Acceptable, borderline-high ( $75^{\text {th }}$ percentiles), and high ( $90^{\text {th }}$ percentiles) were $<75,75-99$, and 100 respectively.

- TG level for those from 10-19 years: Acceptable, borderline-high $\left(75^{\text {th }}\right.$ percentiles), and high ( $90^{\text {th }}$ percentiles) were $<90,90-129$, and 130 respectively.

- HDL-C: Acceptable, borderline-low ( $75^{\text {th }}$ percentiles), and low ( $10^{\text {th }}$ percentiles) were $>45,40-45$, and $<40$ respectively.

Measurement of oxidant and antioxidant activities: Determination of plasma malondialdehyde (MDA) concentration was determined spectrophotometrically (Cary UV/VIS double beam spectrophotometer, 100 V/VIS, Agilent, Australia) using the biodiagnostic MAD assay kit, by the method of Satoh [15]. Thiobarbituric acid (TBA) reacts with MDA in acidic medium at $95^{\circ} \mathrm{C}$ for $30 \mathrm{~min}$ to form thiobarbituric acid reactive product. The absorbance of the resulting pink product can be measured at $534 \mathrm{~nm}$.

Catalase activity was determined spectrophotometrically using the biodiagnostic catalase assay kit, determination necessitates that first catalase reacts with a known quantity of $\mathrm{H}_{2} \mathrm{O}_{2}$ and then the reaction to be stopped after exactly one minute with catalase inhibitor

In the presence of peroxidase (HPR), the remaining $\mathrm{H}_{2} \mathrm{O}_{2}$ reacts with 3,5-Dichloro-2-hydroxybenzene sulfonic acid (DHBS) and 4aminophenazone (AAP) to form a chromophore with a color intensity inversely proportional to the amount of catalase in the original sample [16].

Glutathione S transferase (GST) activity was assessed spectrophotometrically [17]. The biodiagnostic GST assay kit measures total GST activity (cytosolic and microsomal) by measuring the conjugation of 1-chloro-2, 4-dinirobenzene (CDNB) with reduced glutathione (GSH). The conjugation is accompanied by an increase in absorbance at $340 \mathrm{~nm}$. The rate of this increment is directly proportional to the GST activity in the sample.

Serum Total Antioxidant Capacity (TAC) was assessed colorimetrically [18].The biodiagnostic TAC assay kit measured the capacity of the biological fluids to inhibit the production of thiobarbituric acid reactive substances (TBARS) from sodium benzoate under the influence of free ROS derived from Fenton's reaction. 
Citation: Ebeid FSE, Baioumi AY, Elzaree F, Ibrahim FA (2018) Obesity in Egyptian Children: Influence of Oxidant-Antioxidant Status on Lipid and Glucose Homeostasis. J Steroids Horm Sci 9: 194. doi:10.4172/2157-7536.1000194

Page 3 of 7

Vitamin E was determined using competitive-ELISA, vitamin E in the sample or standard competes with a fixed amount of vitamin $\mathrm{E}$ on the solid phase supporter for sites on the Biotinylated Detection Antibody specific to vitamin E. After washing excess conjugate and unbound sample or standard, Avidin conjugated to Horseradish Peroxidase (HRP) is added and incubated. Then a TMB substrate solution is added and the enzyme-substrate reaction is terminated after sulphuric acid solution was added and the color change is measured spectrophotometrically at a wavelength of $450 \mathrm{~nm} \pm 2 \mathrm{~nm}$. In children, normal level is $3-18.4 \mu \mathrm{g} / \mathrm{mL}$ [19].

\section{Statistical analysis}

Data were collected, verified, coded and fed to the Statistical Package for Social Science (IBM SPSS) version 20 (Armonk, NY: IBM Corp 2011). Qualitative data presented as number and percentages while quantitative data presented as mean, standard deviations and ranges when parametric and median with interquartile ranges (IQR) when non parametric. The comparison between two groups with qualitative data were done by using Chi-square test and/or Fisher exact test was used when the expected count in any cell was found less than five. Independent t-test and Mann-Whitney test was used to compare between two groups regarding parametric and non-parametric quantitative data respectively. Spearman correlation coefficients were used to assess the correlation between two quantitative parameters in the same group. The confidence interval was set to $95 \%$ and the margin of error accepted was set to $5 \%$, therefore, the p-value was considered significant $<0.05$.

\section{Results}

Fifty-two children and adolescents with obesity, defined as a BMI at or above the $95^{\text {th }}$ percentile for children and teens of the same age and sex were recruited. Twenty four $(46.2 \%)$ patients were pre-pubertal (Tanner stage 1), 13 (25\%) in puberty (Tanner stage 2-3), 15 (28.8\%) were completing puberty (Tanner stage $4-5$ ).

There was a prevalence of positive family history of obesity, hypertension, and type 2 diabetes $(96.2,76.9$, and $55.8 \%$ respectively). Nearly all the studied obese children had positive family history of obesity (96.2\%), as illustrated in Table 1.

\begin{tabular}{|c|c|}
\hline Clinico-demographic characteristics & Children with obesity $(\mathrm{N}=52)$ \\
\hline Age (years) ${ }^{*}$ & $10.96 \pm 3.75$ \\
\hline Gender, Boys: Girls N (\%) & $30(57.7 \%): 22(42.3 \%)$ \\
\hline Family History of obesity: N (\%) & $50(96.2 \%)$ \\
\hline Family History of type 2 DM: N (\%) & $29(55.8 \%)$ \\
\hline Family History of HTN, N (\%) & $40(76.9 \%)$ \\
\hline Height $(\mathrm{cm})^{*}$ & $137.87 \pm 18.25$ \\
\hline Height Percentile* & $41.56 \pm 36.80$ \\
\hline Height SDS <-2, N (\%) & $9(17.3 \%)$ \\
\hline Weight (kilogram)* & $66.94 \pm 30.79$ \\
\hline Weight SDS <2, N (\%) & $9(17.3 \%)$ \\
\hline Weight SDS 2-3, N (\%) & $38(73.1 \%)$ \\
\hline
\end{tabular}

\begin{tabular}{|c|c|}
\hline Weight SDS >3, N (\%) & $5(9.6 \%)$ \\
\hline $\mathrm{BMI}^{*}$ & $33.60 \pm 9.78$ \\
\hline BMI Percentile* & $98.52 \pm 1.11$ \\
\hline BMI z-score $>2-<3, n \%$ & $49(94.2 \%)$ \\
\hline BMI z-score > 3, n \% & $3(5.8 \%)$ \\
\hline Waist circumference $(\mathrm{cm})^{*}$ & $87.85 \pm 17.86$ \\
\hline Hip circumference $(\mathrm{cm})^{*}$ & $91.10 \pm 18.63$ \\
\hline Waist/hip ratio* & $0.98 \pm 0.12$ \\
\hline Systolic blood pressure $(\mathrm{mmHg})$ & $115.10 \pm 13.63$ \\
\hline$<90^{\text {th }}$ percentile $n \%$ & $26(50.0 \%)$ \\
\hline $90^{\text {th }}$ to $<95^{\text {th }}$ percentile $n \%$ & $6(11.5 \%)$ \\
\hline$\geq 95^{\text {th }}$ percentile $\mathrm{n} \%$ & $20(38.5 \%)$ \\
\hline Diastolic blood pressure $(\mathrm{mmHg})$ & $74.62 \pm 11.37$ \\
\hline$<90^{\text {th }}$ percentile $\mathrm{n} \%$ & $26(50.0 \%)$ \\
\hline $90^{\text {th }}$ to $<95^{\text {th }}$ percentile $\mathrm{n} \%$ & $8(15.4 \%)$ \\
\hline$\geq 95^{\text {th }}$ percentile $\mathrm{n} \%$ & $18(34.6 \%)$ \\
\hline
\end{tabular}

Table 1: Clinical and demographic characteristics of the studied children with obesity.

Most of the studied obese children does not have short stature, only nine $(17.3 \%)$ were short. Three children (5.8\%) had BMI more than three. There was a high prevalence of hypertension in the studied obese children. Laboratory characteristics of the studied obese subjects are illustrated in Table 2.

\begin{tabular}{|l|l|}
\hline Laboratory characteristics & * \\
\hline Serum cholesterol $(\mathrm{mg} / \mathrm{dl})$ & $\begin{array}{l}\text { Children } \\
\mathbf{( N = 5 2 )}\end{array}$ \\
\hline Serum triglyceride $(\mathrm{mg} / \mathrm{dl})$ & $172.13 \pm 30.45(110-250)$ \\
\hline Low-density lipoprotein (mg/dl) & $110.19 \pm 46.11(50-353)$ \\
\hline High-density lipoprotein (mg/dl) & $113.25 \pm 28.37(77-189)$ \\
\hline Fasting blood sugar (mg/dl) & $45.08 \pm 9.52(26-70)$ \\
\hline Fasting serum insulin (mIU/L) & $89.00 \pm 9.01(75-120)$ \\
\hline HOMA-IR ${ }^{\#}$ & $9.04 \pm 3.21(4-18)$ \\
\hline HOMA-\%B\# & $1.17 \pm 0.42(0.5-2.27)$ \\
\hline HOMA-\%S\# & $108.17 \pm 26.41(75-223)$ \\
\hline Plasma malondialdehyde (MDA) (nmol/ml) & $9.44 \pm 3.07(4-17)$ \\
\hline Catalase (U/L) & $57.37 \pm 18.18(23-90)$ \\
\hline Glutathione S Transferase (U/L) & $10.19 \pm 4.41(4-22)$ \\
\hline Serum Total Antioxidant Capacity (TAC) (mM/L) & $0.83 \pm 0.34(0.32-1.65)$ \\
\hline
\end{tabular}


Citation: Ebeid FSE, Baioumi AY , Elzaree F, Ibrahim FA (2018) Obesity in Egyptian Children: Influence of Oxidant-Antioxidant Status on Lipid and Glucose Homeostasis. J Steroids Horm Sci 9: 194. doi:10.4172/2157-7536.1000194

Page 4 of 7

Vitamin $E(\mu \mathrm{g} / \mathrm{mL})$

$7.88 \pm 3.15(2.69-16)$

Table 2: Laboratory characteristics of the studied children with obesity.

According to NCEP Expert Panel on Cholesterol Levels in Children; there were $29(55.8 \%), 7(13.5 \%), 16(30.7 \%)$ patients who had acceptable, borderline-high $\left(75^{\text {th }}\right.$ percentiles $)$, and high $\left(90^{\text {th }}\right.$ percentiles) LDL-C respectively. There were 4 (14.8\%), 1 (40.8\%), 12 (44.4\%) patients aged $0-9$ years (27 patients) who had acceptable, borderline-high $\left(75^{\text {th }}\right.$ percentiles), and high $\left(90^{\text {th }}\right.$ percentiles) TG levels respectively. There were 7 (28\%), 14 (56\%), 4 (16\%) patients aged 10 -19 years (25 patients) who had acceptable, borderline-high $\left(75^{\text {th }}\right.$ percentiles), and high ( $90^{\text {th }}$ percentiles) TG levels respectively. In contrast, there were 23 (44.2\%), 15 (28.8\%), 14 (24.9\%) patients who had acceptable, borderline-low $\left(75^{\text {th }}\right.$ percentiles), and low $\left(10^{\text {th }}\right.$ percentiles) HDL-C. Only one patient had vitamin E below the normal level. Plasma malondialdehyde (MDA), GST were significantly higher in obese children. Whereas catalase, TAC, and vitamin E were significantly lower in obese children in comparison to healthy-weight children as depicted in Table 3.

\begin{tabular}{|c|c|c|c|c|}
\hline Variables & $\begin{array}{l}\text { Control group } \\
\mathrm{N}=\mathbf{2 0}\end{array}$ & Children with obesity $\mathrm{N}=52$ & $\begin{array}{l}\text { Test } \\
\text { value }\end{array}$ & P-value \\
\hline Sex; Female: Male n (\%) & 10 (50.0\%): $10(50.0 \%)$ & 22 (42.3\%): 30 (57.7\%) & $0.346^{*}$ & 0.556 \\
\hline \multirow[t]{2}{*}{ Age ${ }^{\circ}$} & $10.70 \pm 4.08$ & $10.96 \pm 3.75$ & \multirow[t]{2}{*}{$-0.259^{\circ}$} & \multirow[t]{2}{*}{0.797} \\
\hline & $(4-16)$ & $(3-17)$ & & \\
\hline \multirow[t]{2}{*}{ Plasma malondialdehyde (MDA) (nmol/ml) } & $2.35 \pm 1.18$ & $9.44 \pm 3.07$ & \multirow[t]{2}{*}{$-10.012^{\circ}$} & \multirow[t]{2}{*}{$<0.001$} \\
\hline & $(1-4)$ & $(4-17)$ & & \\
\hline \multirow[t]{2}{*}{ Catalase $(\mathrm{U} / \mathrm{L})^{\bullet}$} & $119.15 \pm 24.48$ & $57.37 \pm 18.18$ & \multirow[t]{2}{*}{$11.689^{\circ}$} & \multirow[t]{2}{*}{$<0.001$} \\
\hline & $(80-164)$ & $(23-90)$ & & \\
\hline \multirow[t]{2}{*}{ Glutathione S Transferase (U/L) ${ }^{\circ}$} & $1.90 \pm 0.97$ & $10.19 \pm 4.41$ & \multirow[t]{2}{*}{$-8.297^{\bullet}$} & \multirow[t]{2}{*}{$<0.001$} \\
\hline & $(1-4)$ & $(4-22)$ & & \\
\hline \multirow{2}{*}{$\begin{array}{l}\text { Serum Total Antioxidant Capacity (TAC) } \\
(\mathrm{mM} / \mathrm{L})^{\circ}\end{array}$} & $1.28 \pm 0.67$ & $0.83 \pm 0.34$ & \multirow[t]{2}{*}{$3.803^{\circ}$} & \multirow[t]{2}{*}{$<0.001$} \\
\hline & $(0.6-2.98)$ & $(0.32-1.65)$ & & \\
\hline \multirow[t]{2}{*}{ Vitamin $E(\mu \mathrm{g} / \mathrm{mL})^{\cdot}$} & $14.90 \pm 4.81$ & $7.88 \pm 3.15$ & \multirow[t]{2}{*}{$7.256^{\circ}$} & \multirow[t]{2}{*}{$<0.001$} \\
\hline & $(9-25)$ & $(3-16)$ & & \\
\hline
\end{tabular}

Table 3: Comparison of oxidant and antioxidant markers between obese children and healthy-weight controls.

The correlations of the relationships between the oxidativeantioxidative status of the obese children and clinical-laboratory characteristics are illustrated in Table 4. Both MDA and GST correlated positively with anthropometric measures (weight, height,
BMI, waist circumference, hip circumference), triglyceridess, fasting insulin, and HOMA-IR. Whereas MDA correlated positively with cholesterol, and GST correlated positively with LDL.

\begin{tabular}{|c|c|c|c|c|c|c|c|c|c|c|}
\hline & \multicolumn{2}{|c|}{ Malondialdehyde } & \multirow{2}{*}{$\begin{array}{l}\text { Catalase } \\
r\end{array}$} & \multirow[b]{2}{*}{$P$} & \multicolumn{2}{|c|}{$\begin{array}{l}\text { Glutathione } \\
\text { Transferase }\end{array}$} & \multicolumn{2}{|c|}{$\begin{array}{ll}\text { Total } & \text { Antioxidant } \\
\text { Capacity } & \end{array}$} & \multicolumn{2}{|c|}{ Vitamin E } \\
\hline & $\mathrm{r}$ & $\mathrm{P}$ & & & $\mathrm{r}$ & $\mathrm{P}$ & $\mathrm{r}$ & $P$ & $\mathrm{r}$ & $\mathrm{P}$ \\
\hline Age (Years) & -0.13 & 0.359 & 0.196 & 0.163 & -0.149 & 0.292 & 0.279 & 0.045 & 0.038 & 0.79 \\
\hline Weight (Kg) & 0.763 & 0 & -0.694 & 0 & 0.686 & 0 & -0.605 & 0 & -0.476 & 0 \\
\hline Height (cm) & 0.491 & 0 & -0.453 & 0.001 & 0.407 & 0.003 & -0.397 & 0.004 & -0.251 & 0.073 \\
\hline BMI $\left(\mathrm{Kg} / \mathrm{m}^{2}\right)$ & 0.755 & 0 & -0.668 & 0 & 0.684 & 0 & -0.588 & 0 & -0.506 & 0 \\
\hline $\begin{array}{l}\text { Waist circumference } \\
(\mathrm{cm})\end{array}$ & 0.5 & 0 & -0.401 & 0.003 & 0.474 & 0 & -0.326 & 0.018 & -0.288 & 0.038 \\
\hline $\begin{array}{l}\text { Hip } \\
(\mathrm{cm})\end{array}$ & 0.531 & 0 & -0.461 & 0.001 & 0.473 & 0 & -0.358 & 0.009 & -0.186 & 0.186 \\
\hline Waist/hip ratio & -0.099 & 0.486 & 0.134 & 0.343 & -0.033 & 0.817 & 0.099 & 0.483 & -0.052 & 0.715 \\
\hline
\end{tabular}


Citation: Ebeid FSE, Baioumi AY, Elzaree F, Ibrahim FA (2018) Obesity in Egyptian Children: Influence of Oxidant-Antioxidant Status on Lipid and Glucose Homeostasis. J Steroids Horm Sci 9: 194. doi:10.4172/2157-7536.1000194

Page 5 of 7

\begin{tabular}{|c|c|c|c|c|c|c|c|c|c|c|}
\hline $\begin{array}{l}\text { Systolic blood } \\
\text { pressure }(\mathrm{mmHg})\end{array}$ & 0.353 & 0.01 & -0.215 & 0.125 & 0.293 & 0.035 & -0.14 & 0.321 & -0.187 & 0.184 \\
\hline $\begin{array}{l}\text { Diastolic blood } \\
\text { pressure }(\mathrm{mmHg})\end{array}$ & 0.429 & 0.002 & -0.3 & 0.031 & 0.273 & 0.05 & -0.223 & 0.112 & -0.218 & 0.121 \\
\hline $\begin{array}{l}\text { Serum } \\
(\mathrm{mg} / \mathrm{dl})\end{array}$ & 0.45 & 0.001 & -0.474 & 0 & 0.363 & 0.008 & -0.367 & 0.007 & -0.199 & 0.158 \\
\hline $\begin{array}{l}\text { Serum } \\
\text { (mg/dl) }\end{array}$ triglyceride & 0.363 & 0.008 & -0.315 & 0.023 & 0.338 & 0.014 & -0.272 & 0.051 & -0.204 & 0.147 \\
\hline $\begin{array}{l}\text { Low-density } \\
\text { lipoprotein (mg/dl) }\end{array}$ & 0.243 & 0.083 & -0.383 & 0.005 & 0.307 & 0.027 & -0.262 & 0.061 & -0.134 & 0.343 \\
\hline $\begin{array}{l}\text { High-density } \\
\text { lipoprotein (mg/dl) }\end{array}$ & -0.055 & 0.699 & 0.144 & 0.308 & -0.081 & 0.567 & -0.007 & 0.959 & -0.012 & 0.932 \\
\hline $\begin{array}{l}\text { Fasting blood sugar } \\
\text { (mg/dl) }\end{array}$ & 0.105 & 0.459 & -0.205 & 0.145 & 0.237 & 0.09 & -0.127 & 0.371 & -0.141 & 0.319 \\
\hline $\begin{array}{l}\text { Fasting serum insulin } \\
\text { (mlU/L) }\end{array}$ & 0.279 & 0.045 & -0.275 & 0.048 & 0.296 & 0.033 & -0.262 & 0.06 & -0.145 & 0.304 \\
\hline HOMA-IR & 0.274 & 0.049 & -0.277 & 0.047 & 0.298 & 0.032 & -0.254 & 0.069 & -0.153 & 0.278 \\
\hline HOMA-\%B" & 0.199 & 0.156 & -0.116 & 0.415 & 0.116 & 0.415 & -0.15 & 0.288 & -0.041 & 0.774 \\
\hline HOMA-\%S & -0.17 & 0.227 & 0.213 & 0.13 & -0.229 & 0.102 & 0.206 & 0.142 & 0.093 & 0.511 \\
\hline
\end{tabular}

Table 4: Correlation between the oxidative and anti-oxidative markers of the obese children and selected clinical and laboratory characteristics.

Both catalase and TAC correlated negatively with anthropometric measures (weight, height, BMI, waist circumference, hip circumference), and cholesterol. Furthermore, catalase correlated negatively with diastolic blood pressure, triglyceridess, LDL, fasting insulin, and HOMA-IR, but positively with the age. Vitamin E only correlated with anthropometric measures (weight, BMI, waist circumference).

\section{Discussion}

Childhood obesity is a rapidly increasing worldwide health problem with serious social and medical consequences [20]. The World Health Organization (WHO) in 2012 reported that around 44 million (6.7\%) children aged $<5$ years old worldwide were overweight or obese [21]. The prevalence of overweight and obesity among adolescents in Arab countries ranged from $18 \%$ to $44 \%$ [22]. In general, overweight has been found to be more prevalent than obesity in both genders. This does not apply to adolescents where obesity was higher among Egyptian girls than boys [23].

Oxidative stress, a condition of imbalance between oxidant and antioxidant systems in favor of the oxidative system [24], may be the stem-root of obesity. Adipose tissue is metabolically active and secretes hormones and cytokines, consequently excess fat tissue with ROS generation triggers the oxidative stress and pro-inflammatory cytokine release [25]. Furthermore, excess free fatty acids (FFA) in children with obesity leads to compromised glucose metabolism, resulting in mitochondrial overload with energy substrates [26].

Increased levels of oxidants produced in pathophysiological conditions, antioxidant systems such as catalase (CAT), vitamin E have been developed in order to protect biomolecules from the deleterious effects of ROS [20]. The high production of ROS is an contributing factor in destroying the antioxidant enzymes resulting in depletion of the antioxidant activities in children with obesity [27] which may have deleterious effects on $\mathrm{RBC}$ membranes, resulting in lipid peroxidation enhancing the production of MDA concentrations, which in turn has additional toxic effects on antioxidant enzymes [28].

In the current study, the common approach in the measurement of oxidative stress which is the determination of MDA was followed. In addition the practical parameter, total antioxidant status (TAS), was also measured. We reported that oxidative markers in the form of plasma MDA and GST were significantly higher in obese children, whereas antioxidants in the form of catalase, TAC, and vitamin $\mathrm{E}$ were significantly depleted in obese children in comparison to healthyweight children. This finding is in agreement with the work of Ustundag and his colleagues who reported elevation of plasma MDA in prepubertal obese children when compared with healthy controls and MDA was well correlated with BMI. In contrast to the increase in oxidative stress, antioxidant activities of glutathione peroxidase were decreased in obese prepubertal children [28].

Childhood obesity is an alarming condition that predisposed to chronic adulthood diseases such as CVD, insulin resistance, type 2 diabetes mellitus, metabolic syndrome and adulthood obesity (Kilic et al.). In the current study there was a high prevalence of positive family history of obesity, hypertension, and type 2 diabetes $(96.2 \%, 76.9 \%$, and $55.8 \%$ respectively) and high prevalence of hypertension in the studied obese children.

Long-term accumulation of energy substrates causes FFA passage especially from visceral adipose tissue to the blood. The increased FFA causes increased cell differentiation and mitochondrial workload, consequently increased the release of ROS products, which are especially destructive for specific organelles and DNA [26]. In our study, lipid profiles in the obese children were assessed and we found that $16(30.7 \%)$ had high levels $\left(90^{\text {th }}\right.$ percentiles) of low-density 
lipoprotein (LDL-C) and triglycerides and 14 (24.9\%) had low levels ( $10^{\text {th }}$ percentiles) of high-density lipoprotein (HDL-C).

In the current Egyptian study correlation analysis was used to investigate the mutual relationship between the oxidative status of obese children and their clinical-laboratory characteristics to highlight those at risk. Both MDA and GST correlated positively with anthropometric measures, triglycerides, fasting insulin, and HOMAIR. Both catalase and TAC correlated negatively with anthropometric measures, and cholesterol. Furthermore, catalase correlated negatively with diastolic blood pressure, triglycerides, LDL, fasting insulin, and HOMA-IR, but positively with the age. Our findings highlight that the oxidative stress augments insulin resistance which decreases insulin release from the pancreas. Furthermore, we reported that obese children showed an increase in serum concentrations of LDLs and triglycerides, GST, HOMA-IR and HOMA-\%B indices, as well as a reduction in the HOMA-\%S.

A Mexican study investigated the relationship between obesity, oxidative stress, heme oxygenase-1 (HO-1), and insulin in children aged 3 to 5 years. The authors concluded that obese preschool children showed a chronic state of oxidative stress, an increase of HO-1, and an incipient state of insulin resistance. This increased ROS could be one of the leading factors involved in insulin resistance and Ox-LDL increase from the preschool stage [29].

A Spanish study similarly evaluated the presence of oxidative stress in 68 obese children aged between 6 and 14 years without comorbidities. They found that the levels of MDA and CG were significantly higher in children with $\mathrm{SDS}-\mathrm{BMI} \geq 3$. The glutathione peroxidase (GPx) activity was increased, while the erythrocytereduced glutathione [GSH] concentration was lower in obese children compared with non-obese children. MDA was the sole marker of oxidative damage that was positively correlated with SDS-BMI and negatively correlated with HDL-C. In multiple regression analysis, they confirmed that SDS-BMI and HDL-C were determinants of MDA. The authors recommended that providing foods with high antioxidant capacity in addition to a hypocaloric diet is crucial for the treatment of obese children [30].

A cross-sectional Mexican study evaluated the relationship between micronutrient status and obesity, lipids, insulin resistance and chronic inflammation in 197 school-aged children. They found that vitamin E: lipids were negatively associated with BMI, waist-to-height ratio (WHR) and body and abdominal fat and also negatively associated with insulin and CRP. Interaction analysis showed that children who were overweight and obese who also had low concentrations of vitamin $\mathrm{E}$ had significantly lower glucose and triglyceridess and higher LDL concentrations [31]. Major limitation of the present study were the small numbers of recruited patients, the cross-sectional nature of the study without follow-up, and the lack of assessment of the physical activities and diet.

\section{Conclusions}

There is a substantial burden of oxidative stress in the obese children which necessitates improving the understanding and management of its influence on childhood obesity.

\section{Key Messages}

- The prevalence of children with obesity is rapidly increasing worldwide.
- In the current study demonstrated a high prevalence of positive family history of obesity that may indicate that environmental factors play an important role.

- In the current study there was a high prevalence of hypertension and type 2 diabetes in children with obesity.

- Existing approaches to prevention and interventions have limited success.

\section{References}

1. Camilla SM, Benjamin R, Carina SB, Camilla SA, Lise GA, et al. (2003) Trends in prevalence of overweight and obesity in danish infants, children and adolescents-are we still on a plateau? PLoS One 8: e69860.

2. Olusi SO (2002) Obesity is an independent risk factor for plasma lipid peroxidation and depletion of erythrocyte cytoprotectic enzymes in humans. Int J Obes Relat Metab Disord 26: 1159-1164.

3. Jane VH, Balz F (2003) Obesity and oxidative stress: A direct link to CVD? Arterioscler Thromb Vasc Biol 23: 365-367.

4. Vincent HK, Taylor AG (2006) Biomarkers and potential mechanisms of obesity-induced oxidant stress in humans. Int J Obes 30: 400-418.

5. Barlow SE and the Expert Committee (2007) Expert committee recommendations regarding the prevention, assessment, and treatment of child and adolescent overweight and obesity: Summary report. Pediatrics 120: Supplement December,S164-S192.

6. Laurence MGS, Chris R, Nancy FK and Centers for Disease Control and Prevention (2010) Use of world health organization and CDC growth charts for children aged 0-59 months in the United States. Morbidity and mortality weekly report (MMWR) 59: 1-15.

7. National high blood pressure education program working group on high blood pressure in children and adolescents (NHBPEP) (2004) The fourth report on the diagnosis, evaluation, and treatment of high blood pressure in children and adolescents. Pediatrics 114: 555-76.

8. https://www.rcpch.ac.uk/system/files/protected/page/

Educational_materials_2-18_final.pdf

9. Anne F, Suzanne BJ, ArlanR, Barrie A, Carolyn AH (1986) Subjective symptoms, blood glucose estimation, and blood glucose concentrations in adolescents with diabetes. Diabetes Care 9: 236-243.

10. Diabetes Trial Unit (2017) The oxford centre for diabetes, endocrinology and metabolism.

11. Laura SK, Daphne CH, Katy M (2015) Reliability, validity, and diagnostic value of a pediatric bioelectrical impedance analysis scale. Child Obes 11: 650-655.

12. William TF, Robert IL, Donald SF (1972) Estimation of the concentration of low-density lipoprotein cholesterol in plasma, without use of the preparative ultracentrifuge. Cli Chem 18: 499-502.

13. Bachorik PS (1989) Measurement of total cholesterol, HDL-cholesterol, and LDL-cholesterol. Cli Lab Med 9: 61.

14. National Heart, Lung, and Blood Institute (2017). Health-pro guidelines current cardiovascular health pediatric guidelines: Chapter9.

15. Satoh K (1978) Serum lipid peroxide in cerebrovascular disorders determined by a new colorimetric method. Clin Chim Acta 90: 37-43.

16. Aebi H (1984) Catalase in vitro. Methods Enzymology 105: 121-126.

17. William HH, Michael JP, William BJ (1974) Glutathione S-transferases: The first enzymatic step in mercapturic acid formation. J Biol Chem 249: 7130-7139.

18. Koracevic D, Koracevic G, Djordjevic V, Andrejevic S, Cosic V (2001) Method for the measurement of antioxidant activity in human fluids. J Clin Pathol 54: 356-361.

19. Richard AM, Matthew RP (2011) Henry's Clinical Diagnosis and Management by Laboratory Methods. 22nd ed. Philadelphia: Elsevier Saunders.

20. Elif K, Ömer FÖ, Aybala ET, Hayriye E, Emel T, et al. (2016) Oxidative Stress Status in Childhood Obesity: A Potential Risk Predictor. Med Sci Monit 22: 3673-3679. 
Citation: Ebeid FSE, Baioumi AY, Elzaree F, Ibrahim FA (2018) Obesity in Egyptian Children: Influence of Oxidant-Antioxidant Status on Lipid and Glucose Homeostasis. J Steroids Horm Sci 9: 194. doi:10.4172/2157-7536.1000194

Page 7 of 7

21. World Health Organization (2014) World Health Statistics full report.

22. Abdulrahman OM, Abdelmonem SH, Omar O (2011) The paradox of nutrition-related diseases in the Arab countries. J Environ Res Public Health 8: 3637-3671.

23. Abdulrahman OM, Mariam AM, Reema T, Osama AL, Essa YHA, et al. (2012) Prevalence of Overweight and Obesity among Adolescents in Seven Arab Countries: A Cross-Cultural Study. J Obes 2012.

24. Sies H (2015) Oxidative stress: A concept in redox biology and medicine. Redox Biol 4: 180-83.

25. Alba FS, Eduardo MS, Mirandeli B, Jaime ES, Ángel MG, et al. (2011) Inflammation, oxidative stress and obesity. Int J Mol Sci 12: 3117-3132.

26. Rzheshevsky AV (2013) Fatal "Triad": Lipotoxicity, oxidative stress, and phenoptosis. Biochemistry (Mosc) 78: 991-1000.

27. Albuali WH (2014) Evaluation of oxidant-antioxidant status in overweight and morbidly obese Saudi children .World J Clin Pediatr 3: 6-13.
28. Bilal U, Serdal G, Denizmen A, Mehmet T, Erdal Y (2007) Oxidative status and serum leptin levels in obese prepubertal children. Cell Biochem Funct 25: 479-483.

29. Enrique CM, Raul VP, Edna PA, Selva RA (2016) Obesity, oxidative stress, and their effect on serum heme oxygenase-1 concentrations and insulin in children aged 3 to 5 years in a pediatric hospital of the ministry of health cdmx. Child Obes 12: 474-481.

30. Pilar CF, Laura BG, Raquel SJ, Cristina MM, Victoria VB (2010) Is obesity associated with oxidative stress in children? Int J Pediatr Obes 5: 56-63.

31. Olga PG, Dolores R, MaríaCC, Guadalupe M, Mariela C, et al.(2013) Zinc, Iron and Vitamins $\mathrm{A}, \mathrm{C}$ and $\mathrm{E}$ are associated with obesity, inflammation, lipid profile and insulin resistance in mexican school-aged children. Nutrients 5: 5012-5030. 